OPEN ACCESS

Edited by:

Klaus Jahn,

Schoen Clinic Bad Aibling, Germany

Reviewed by:

Carmen Krewer,

Schön Klinik, Germany

Jan Mehrholz,

SRH Hochschule für

Gesundheit, Germany

*Correspondence:

Diane M. Wrisley

dwrisley@csm.edu;

drdmwrispt@gmail.com

Specialty section:

This article was submitted to

Neurorehabilitation,

a section of the journal

Frontiers in Neurology

Received: 19 January 2021

Accepted: 27 May 2021

Published: 23 June 2021

Citation:

Wrisley DM, McLean G, Hill JB and Oddsson LIE (2021) Long-Term Use

of a Sensory Prosthesis Improves

Function in a Patient With Peripheral

Neuropathy: A Case Report.

Front. Neurol. 12:655963

doi: 10.3389/fneur.2021.655963

\section{Long-Term Use of a Sensory Prosthesis Improves Function in a Patient With Peripheral Neuropathy: A Case Report}

\author{
Diane M. Wrisley ${ }^{1,2 *}$, Gillian McLean ${ }^{1,3}$, Jennifer Baity Hill ${ }^{1,4}$ and Lars I. E. Oddsson ${ }^{5,6,7}$ \\ ${ }^{1}$ Department of Physical Therapy, Wingate University, Wingate, NC, United States, ${ }^{2}$ Doctor of Physical Therapy Program, \\ College of St Mary, Omaha, NE, United States, ${ }^{3}$ Fyzical Therapy and Balance Centers, Las Vegas, NV, United States, \\ ${ }^{4}$ OrthoCarolina Outpatient Winston-Salem, Winston-Salem, NC, United States, ${ }^{5}$ Department of Rehabilitation Medicine, \\ Medical School, University of Minnesota, Minneapolis, MN, United States, ${ }^{6}$ Recanati School of Community Health, Ben \\ Gurion University of the Negev, Beersheba, Israel, ${ }^{7}$ RxFunction Inc., Eden Prairie, MN, United States
}

Background: Peripheral neuropathy (PN) can result in either partial or complete loss of distal sensation resulting in an increased fall risk. Walkasins ${ }^{\circledR}$ uses a shoe insert to detect the magnitude and direction of sway and sends signals to a leg unit that provides sensory balance cues. The objective of this case report is to describe the long-term influence of the Walkasins ${ }^{\circledR}$ lower limb sensory neuroprosthesis on balance and gait for an individual with diabetic PN.

Case Description: A 51-year-old male with a 3-year history of PN and a 10-year history of type II diabetes mellitus was fitted bilaterally with Walkasins ${ }^{\circledR}$ and utilized them 8-10 hours/day for more than 2 years. Although, vibration and tactile sensation thresholds were severely impaired at his 1st metatarsophalangeal joint and the lateral malleolus bilaterally he could perceive tactile stimuli from the Walkasins ${ }^{\circledR}$ above the ankles.

Outcomes: Following Walkasins ${ }^{\circledR}$ use, his Activities-specific Balance Confidence Scale (ABC) scores improved from 33 to $80 \%$. His mean Vestibular Activities of Daily Living (VADL) scores decreased from 3.54 to 1. His Functional Gait Assessment (FGA) scores increased from $13 / 30$ to $28 / 30$ and his miniBESTest scores improved from 15/28 to 26/28. Gait speed increased from 0.23 to $1.5 \mathrm{~m} / \mathrm{s}$. The patient described a decrease in pain and cramping throughout his lower extremities and an increase in function.

Discussion: Gait and balance improved with the use of the Walkasins ${ }^{\circledR}$ and participation in a wellness program. This improvement suggests that the use of sensory substitution devices, such as the Walkasins ${ }^{\circledR}$, may replace sensory deficits related to gait and balance dysfunction experienced by patients with PN. Further research is needed to determine if other patients will have a similar response and what the necessary threshold of sensory function is to benefit from use of the Walkasins ${ }^{\circledR}$.

Keywords: balance, sensory substitution, neuroprosthesis, peripheral neuropathy, fall risk, diabetes, case report, gait 


\section{BACKGROUND AND PURPOSE}

Approximately $12 \%$ of the adult population in the United States has been diagnosed with diabetes mellitus with the prevalence in adults $45-64$ being $17 \%$ (1). The prevalence is rising due to aging, obesity and decreases in physical activity (2). Thirty to fifty percent of adults with diabetes present with peripheral neuropathy (PN) (3-6). The number of people with $\mathrm{PN}$ may be higher as many cases are subclinical, undiagnosed, or are underreported $(2,7)$. Peripheral neuropathy can be either motor, autonomic, sensory or a combination of all three (8). The majority of people with $\mathrm{PN}$ experience autonomic neuropathy with the second most common form being sensory neuropathy. With diabetes, the most common type of $\mathrm{PN}$ is sensory (9). Symptoms of PN include autonomic, motor, and sensory dysfunction resulting in balance and gait impairments. People with PN demonstrate increased sway with their eyes closed and more sway response to visual flow $(10,11)$. Decreased use of an ankle strategy is also noted as is decreased reaction time which both can increase the risk of falling (12).

Gait speed and stride length are decreased in people with diabetes $(13,14)$. Persons with PN demonstrate a wide base of support, greater step time variability, greater time spent in double limb support, and impaired pressure distribution of the foot $(14,15)$. People with painful PN demonstrate greater variability in step length and velocity (13). Ankle mobility and power are decreased as well (16). It is thought that the sensory changes that occur with PN contribute to gait impairments (13).

People with PN have an increased risk of falling (14, 17, 18). Approximately $29 \%$ of people with diabetic peripheral neuropathy have experienced a fall in the previous 12 months (19). Peripheral neuropathy is significantly associated with falling and repetitive falling. Fall risk increases when the person is in pain or experiencing gait and balance dysfunction (20). Most falls occur during gait $(14,17,21)$.

Although current physical therapy interventions can improve balance and gait function in people with PN, the improvements are only minimal. In two systematic reviews of interventions for diabetic peripheral neuropathy, lower extremity strengthening was given only a fair recommendation $(22,23)$. All other interventions, including electrotherapy (22) and monochromatic light therapy (22), had insufficient evidence to recommend them for decreasing pain and increasing function (24). Salsabili et al. (24), however, found an improvement in Timed "Up and Go" scores and Falls Efficacy Scale scores following 4 weeks of taskoriented gait and balance training in a case series. Timed "Up \& Go" scores decreased greater than the Minimal Detectable Change (MDC) from an average of 10-7.3 s (25).

The use of plantar electrical stimulation daily for 6 weeks improved gait (stride velocity and stride time) and balance parameters (sway eyes open) as well as vibratory plantar threshold when compared to a control group that also improved but less than the intervention group (26). Gait speeds increased from 0.87 to $0.97 \mathrm{~m} / \mathrm{s}$ in the intervention group and from 0.82 to $0.90 \mathrm{~m} / \mathrm{s}$ in the control group. Considering such marginal changes in outcomes, interventions that can improve gait and balance function in people with PN is needed. The SENSUS device used in the Najafi et al. (26) study was a TENS unit applied to the plantar surface for an hour each night.

Vibrotactile sensory substitution devices have been used experimentally to improve gait and balance function in people with various sensory deficits including older adults at risk for falls and vestibular dysfunction (27-34). Sensory substitution devices may use accelerometers and gyroscopes to replace lost vestibular function or foot pressure sensors to replace lost plantar mechanoreceptor function to help determine the body position in space and improve balance (31). Furthermore, pilot data suggests a possible augmentation effect where gait and balance function may improve although the sense appears clinically intact (e.g., balance-related foot pressure information may enhance balance in patients with vestibulopathy although plantar sensation is intact, and/or vestibular information may enhance balance in PN patients) $(27,31,34)$.

Previously, sensory substitution devices have been used for short periods of time, usually up to 1 month (35). Improvements have been demonstrated with carryover up to 6 months (32) but the use of a device long term as a balance prosthesis to improve gait and balance in people with peripheral neuropathy had not been investigated. Recently we published a paper regarding the 10 week use of Walkasins in people with PN. The subjects improved gait and balance function as demonstrated by improvements in the Functional Gait Assessment (FGA), Timed "Up \& Go," gait speed, and a decrease infall rate (36). The subjects were not allowed to participate in any other form of balance intervention during the 10 weeks of the study. The purpose of this case report is to describe improvements in gait and balance seen in a patient with diabetic PN when wearing Walkasins ${ }^{\circledR}$, a sensory prosthesis, long term (6-8 h/day) for more than 2 years. It is unique from the previous paper as it demonstrates that improvements were seen with the device as well as introducing the role of rehabilitation with the device. The device provides directional specific tactile stimuli based on measurements of plantar center of pressure with a sensor embedded insole placed in the shoe. In a recent randomized cross-over trial, (37) short-term in clinic improvements in both FGA and gait speed associated with wearing the Walkasins ${ }^{\circledR}$ device turned on were demonstrated in a group of patients with $\mathrm{PN}$. The frequency of the tactile stimuli provided by the device is in the range of the clinically used $128 \mathrm{~Hz}$ tuning fork, although the stimulus amplitude is higher. Consequently, patients who may be insensate to the tuning fork may still be able to feel the device stimulus. We hypothesize that the device can replace lost foot pressure sensation with new sensory balance signals that modulate skin mechanoreceptors using tactile stimulators on the calf proximal to the nerve lesion where the patient's sensation is still sufficiently intact $(31,37)$.

\section{CASE DESCRIPTION: PATIENT HISTORY AND SYSTEMS REVIEW}

The patient was a 51-year-old male who was referred for physical therapy due to balance and gait difficulties secondary to diabetic PN. He was referred to the Neurologic Wellness Program at 
Wingate University. The Neurological Wellness Program is a student run (pro-bono) clinic that provides exercise, gait, and balance training to people with neurological disorders who do not have health insurance or have exhausted their insurance.

His primary complaint was that his feet were numb. His past medical history included a 10-year history of type II Diabetes Mellitus, well-controlled with medication, mild back pain, peripheral neuropathy, high blood pressure, and kidney failure. He denied any falls in the past year. He complained of a not being able to feel his feet, walking on bricks, tingling, and pain. He had a diagnosis of primary sensory PN with moderate pain and generalized weakness. Prior to the diagnosis of PN, he was very active playing $20 \mathrm{~h}$ of tennis per week, roller blading and playing basketball. He was a truck driver for many years prior to his diagnosis and had to stop driving as he could not feel his feet.

$\mathrm{He}$ was alert and oriented, appeared cognitively intact and was a good historian. His medication included $81 \mathrm{mg}$ aspirin, sertraline, Lisinopril, meclizine (due to generalized dizziness), pravastatin, chlorpromazine, Lyrica, omeprazole, Apidra, Lantus, iron, vitamin C, B12, and D3. His blood pressure was 150/98 with $\mathrm{O} 2$ saturation of $98 \%$. His integumentary system was normal as was his range of motion except for ankle dorsiflexion to neutral bilaterally. Strength was generally $4 / 5$ with the exception of ankle dorsiflexion which was $3+/ 5$ bilaterally. He ambulated $\sim 0.25$ miles in the community with a straight cane and was independent in all mobility and ADLs. His light touch and sharp/dull sensation was impaired below the knee bilaterally. He was unable to detect the $50 \mathrm{~g}$ monofilament below the knee but was able to detect the $2 \mathrm{~g}$ above the knee. He was unable to detect the $128 \mathrm{~Hz}$ tuning fork at the great toe or the lateral malleolus, but it was intact at the knee bilaterally.

Due to the results of the systems review and observation of his gait in the clinic, the following special tests were completed; The Activities-specific Balance Confidence Scale (ABC) (38), The Vestibular Activities of Daily Living Scale (VADL) (39), 20 ' gait speed, Functional Gait Assessment (FGA) (40), miniBESTest (41), Timed "Up \& Go" (TUG) (42), and cognitive TUG (43). The results of his initial scores on these tests are illustrated in Figures 1, 2. Although he was seen for 6 months prior to using Walkasins, multiple baseline values were not collected except for 2 measures for the FGA.

The Activities-specific Balance Confidence (ABC) test is a 16 item self-efficacy questionnaire that quantifies how confident people are in their ability to balance during the activities (38). The $\mathrm{ABC}$ is scored on a mean with scores ranging from 0 to 100 with higher scores indicating more confidence. The $A B C$ is reliable and valid $(38,44-47)$. The minimal detectable change (MDC) of the $\mathrm{ABC}$ is reported to be $11-15$ points depending on the population $(44,45,48)$. The $\mathrm{ABC}$ has not been evaluated in people with $\mathrm{PN}$. The patient's score on the $\mathrm{ABC}$ prior to intervention was $32 \%$.

The Vestibular Activities of Daily Living Scale (VADL) was developed to quantify a person's ability to perform daily activities and perception of assistance needed during functional activities that challenge balance (39). It contains 28 items ranging from bed mobility to driving a car. The VADL was developed to be scored on a median so that an item can be skipped without affecting the score. We scored it on both a median and mean to increase its responsiveness. The reliability and validity of the VADL has been demonstrated in subjects with vestibular dysfunction although an MDC has not been established $(39,49)$. The patient's mean score on the VADL prior to intervention was 3.5.

Gait speed was calculated on a $20^{\prime}$ walkway with $\sim 4^{\prime}$ acceleration and deceleration space. Calculation of gait speed is considered reliable and valid (50-52). A gait speed of $1.2 \mathrm{~m} / \mathrm{s}$ is necessary to cross the street (53). The MDC for gait speed is 0.09 $\mathrm{m} / \mathrm{s}$ for people with Parkinson Disease (51) and for those with Alzheimer's Disease (52), and $0.109 \mathrm{~m} / \mathrm{s}$ in older adults (54). The patients preferred gait speed was $0.21 \mathrm{~m} / \mathrm{s}$ prior to intervention. He ambulated with a straight cane in the community.

The Functional Gait Assessment (FGA) was initially developed to quantify gait tasks in people with vestibular dysfunction (55). It includes 10 tasks, including gait at normal, slow and fast speeds, gait with head turns, turning, stepping over obstacles, walking tandem, eyes closed, backwards, and stairs, rated on an ordinal scale. It has been shown to be reliable and valid in many populations (40,56-63). The MDC of the FGA has been calculated to be 4 points in people with Parkinson's Disease (59) and 6 points in people with vestibular disorders (58). The Minimal Clinically Important Difference in community dwelling older adults is 4 (64). Scores of $<22 / 30$ indicate increased fall risk in community dwelling older adults (61). The patient's FGA score prior to intervention was $13 / 30$.

The mini-BESTest was developed to guide treatment for balance disorders. It is a revision of the BESTest to decrease the time for administration. It contains 14 items scored on an ordinal scale of $0-2$. It has been shown to be reliable and valid in various populations (65-67). Scores of $<16$ indicate increased risk of falling in older adults (67). The MDC for the mini-BESTest is 3.5 points in people with balance deficits (65). The patient's mini-BESTest score prior to intervention was 15/28.

Timed "Up \& Go" (TUG) is the time it takes a patient to stand from sitting in a chair, walk 3 meters, turn, walk back to the chair and sit down (42). Times $>11 \mathrm{~s}$ indicate increased risk of falls in older, community dwelling older adults $(40,42,68,69)$. The MDC for the Timed "Up \& Go" is $1 \mathrm{~s}$ in people with Type II Diabetes (25). The cognitive Timed “Up \& Go" (cTUG) requires that a cognitive task such as counting backwards by 3 's is performed while completing the test. A $10 \%$ difference between scores on the TUG and the cTUG is considered abnormal (41, $70,71)$. His TUG score was $26 \mathrm{~s}$, and his cognitive TUG was $37 \mathrm{~s}$ prior to intervention.

\section{Intervention}

The Walkasins ${ }^{\circledR}$ is a sensory prosthesis that is intended to replace nerve function used to detect and signal balance related foot pressure sensation that is lost in patients with PN. It is indicated for use by individuals with lower limb sensory peripheral neuropathy who present with gait and balance impairments and are at high risk of falls $(36,37)$. Pressure sensors embedded in shoe inserts measure plantar pressure, an embedded microprocessor and software estimates center of pressure parameters and activates a relevant tactile actuator around the ankle just above the malleoli providing directional 

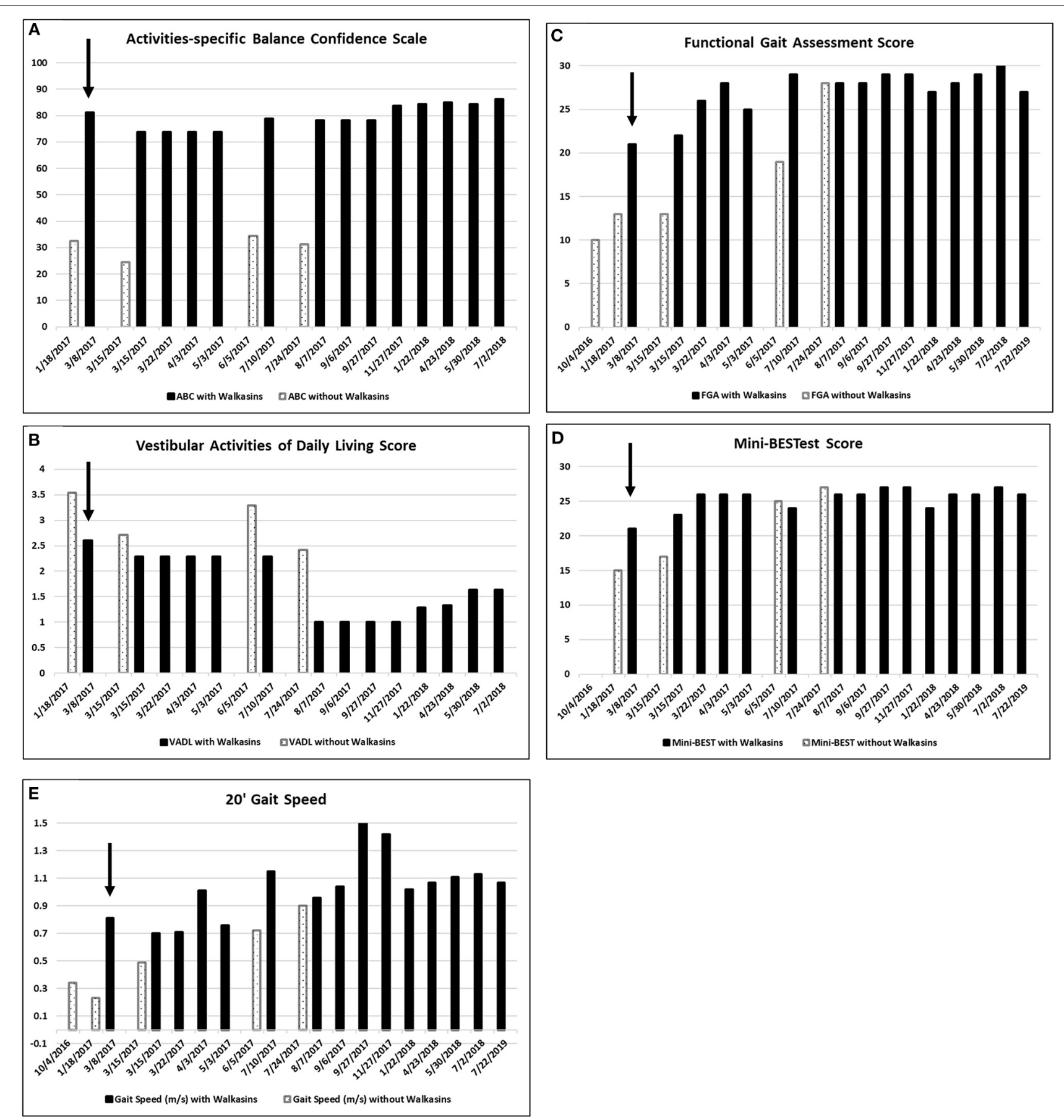

FIGURE 1 | (A) Scores on the Activities-specific Balance Confidence (ABC), (B) the Vestibular Activities of Daily Living (VADL), (the VADL and ABC were not administered on 7/22/2019), (C) Functional Gait Assessment (FGA), (D) Mini-BESTest, and (E) 20' Gait Speed prior to and while wearing the Walkasins ${ }^{\circledR}$. Higher on the ABC, FGA, Mini-BESTest, and 20' Gait speed and lower scores on the VADL are better. He started wearing the Walkasins ${ }^{\circledR}$ on 3/8/2017 noted with an arrow $\downarrow$. Note that occasionally the Walkasins ${ }^{\circledR}$ device was turned off for a day and on those dates his perception of balance and functional ability decreased.

specific information on center of pressure sway to help indicate the position of the body in space. During walking, relevant events of the gait cycle are signaled including heel strike and toe off allowing identification of the stance and swing phases of gait.
The device is currently being investigated in a multi-site longterm clinical trial in a cohort of patients with $\mathrm{PN}$ (walk2Wellness, ClinicalTrials.gov \#NCT03538756). The findings of the first 10 weeks in this trial of Walkasins has demonstrated improvement 


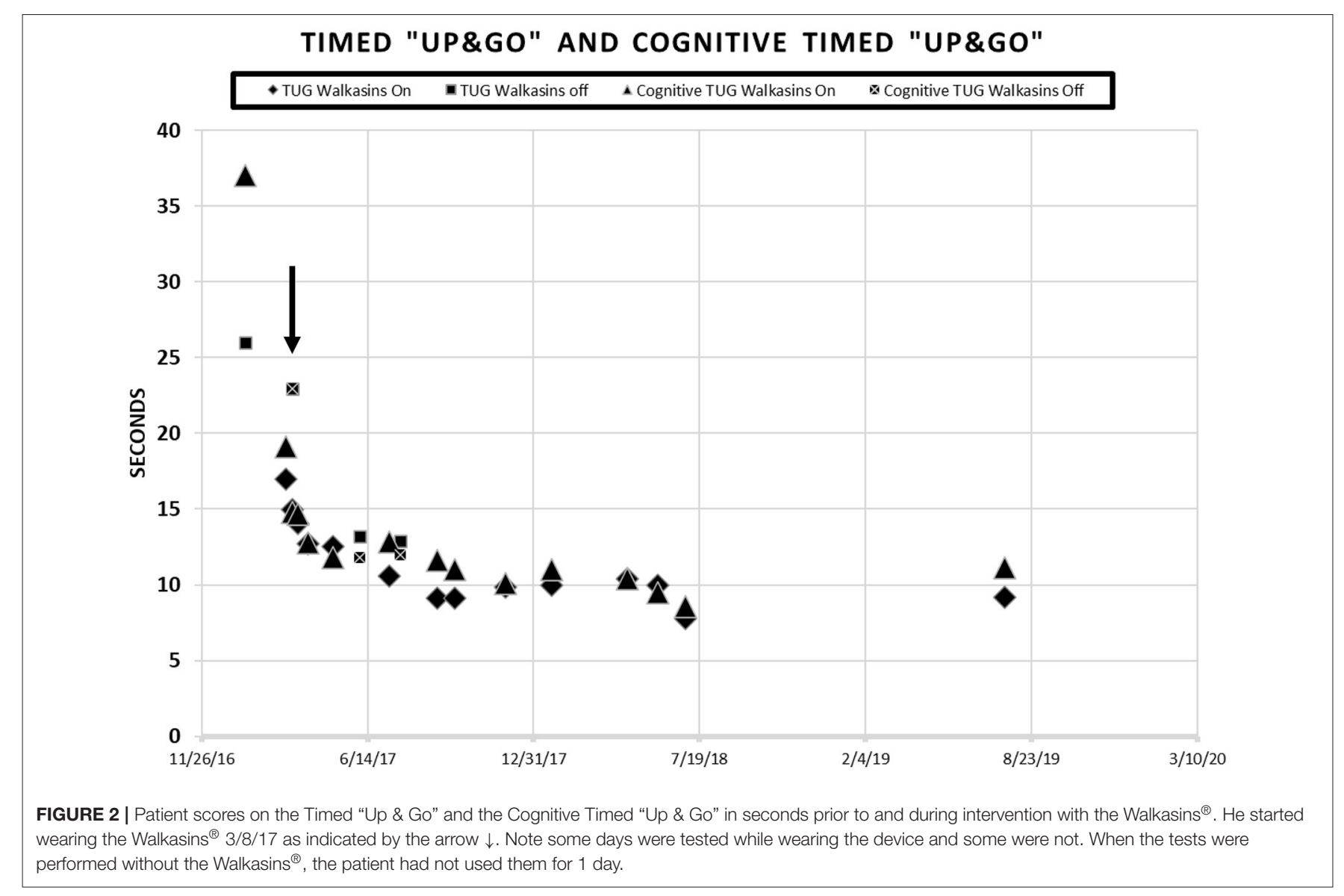

in gait and balance function in 45 adults with PN (37). Previous short -term studies (31) including a recent in clinic randomized cross-over trial showed short-term improvements in gait and balance function (37).

The patient in the current study had been participating in a student run, pro bono neurological wellness program for 2 times a week over a period of 5 months and was receiving gait and balance training prior to the intervention with the Walkasins ${ }^{\circledR}$. Although he had seen some improvement in his gait and balance, he was no longer improving. FGA scores increased from 10 in October to 13 in January (Figure 1C). Based on this he was still at an increased risk of falls (61). He reported decreased visual acuity, due to macular edema, in addition to the peripheral neuropathy, so a decision was made to try the Walkasins ${ }^{\circledR}$ to evaluate its use to maximize his function. The use of the device was approved by the Research Review Board at Wingate University. The patient was fitted with the Walkasins ${ }^{\circledR}$ and was instructed in how to use the sensory information for balance by swaying with the eyes open and closed as well as walking. Despite his loss of sensory function below the knee, he was able to feel the vibration from Walkasins and use the information, therefore it was agreed that a trial of the device was warranted. The patient was able to use the information immediately and improvements in gait and balance measures were noted over time (see Figures 1, 2). The patient wore Walkasins ${ }^{\circledR}$ for more than 2 years while participating in the Neurological Wellness Program sporadically. He was aware of his scores on the outcome measures, completed a home exercise program of gait and balance exercises including encouragement to walk in the community, and received positive feedback as he improved.

\section{RESULTS}

The patient's improvements in the gait and balance measures assessed before and during the intervention are shown in Figures 1, 2. Occasional testing occurred with the device turned off. On those occasions, the Walkasins ${ }^{\circledR}$ had been turned off only for that testing day to see if there was carry over. It should be noted that the patient improved his scores beyond the MDC and beyond the fall risk cutoff for each of the outcome measures within the 1st week of using the device. Surprisingly, the improvements seen with the device in gait and balance appeared to be maintained with the device turned off for 1 day following 3-4 months of initial use. The patient's perception of his balance abilities was substantially less when the device was turned off. From a qualitative perspective, the patient reported that the device was easy to use and had greatly improved his balance. He reported that not only had his balance improved but his leg pain and cramping had decreased. He had increased 
his community ambulation from $<0.25$ miles to over 5 miles. In addition, he had started running down the hallway in the clinic with supervision.

\section{DISCUSSION}

Improvements were seen immediately following donning the Walkasins ${ }^{\circledR}$ and the improvements continued throughout the 2 years follow-up while participating in the exercise program. The patient continues to wear the Walkasins ${ }^{\circledR}$ and maintain improvements, however only the data from the 2 years is presented here. Improvements in outcomes were maintained even with the device turned off for 1 day. The most plausible explanation for why he improved was that the Walkasins ${ }^{\circledR}$ provided sensory information from his insensate feet and transferred the information to an area of intact sensation around his lower leg. It may also be that the information from the device allowed the brain to align and use other sensory inputs to provide a reference of verticality. Similar changes in gait and balance have been documented in our previously published paper on the results of a 10-week trial. This case report demonstrates continued improvements and benefits of using Walkasins. However, the patient in this study demonstrated greater improvements than those in the other study and demonstrated continued improvements as he participated past 10 weeks, in fact his performance peaked between 4 and 6 months (Figures 1, 2).

It was unexpected that the Walkasins ${ }^{\circledR}$ may have played a role in decreasing pain and muscle cramping. The mechanism of this is unclear but it is thought that the new relevant sensory information regarding foot pressure provided from Walkasins ${ }^{\circledR}$ may block the allodynia seen with peripheral neuropathy. What is surprising and harder to explain is that the pain relief continued during periods of the day in which the patient was not wearing the device although the increased level of physical activity by the patient may in itself improve his overall health and fitness leading to less pain.

Another unexpected observation was that the gait and balance improvements were seen even when the device was turned off for a day. It may be that the brain learned to use other sensory inputs for postural control. The patient's perception of his balance abilities decreased as soon as the device was turned off. A possible explanation of the improvements seen with the Walkasins ${ }^{\circledR}$ was due to a placebo effect due to improved confidence. However, this does not seem likely due to his physical performance with the device while turned on. He did know whether the device was on or off during testing as he could tell when it was working. Future research should be conducted to determine what would happen if the device would be turned off for longer periods of time. Since the Walkasins ${ }^{\circledR}$ neuroprosthesis attempts to substitute for lost foot pressure sensation required for balance, it may be hypothesized that overall balance function will deteriorate with the device off.

The patient continued to participate in the Neurological Wellness Program while wearing the Walkasins ${ }^{\circledR}$, making it difficult to determine whether the gait and balance training or wearing of the Walkasins ${ }^{\circledR}$ made the difference in the outcome measures. It is unlikely that the Neurological Wellness Program made that dramatic of a change as he had participated in the program for 5 months before he used the Walkasins ${ }^{\circledR}$, and since his progress had plateaued. Further research is needed to determine the effect of the Walkasins ${ }^{\circledR}$ on gait and balance in persons with insensitive feet.

\section{LIMITATIONS}

There are several limitations of this study: (1) This is a case report so the findings cannot be generalized. (2) The subject continued to participate in a Neurological Wellness Program so the changes may have been due to his continued interventions. (3) The patient was highly motivated, other patients without high motivation may not see such improvements. (4) The patient was relatively young compared to many people with peripheral neuropathy, his improvements may have been greater due to his age.

\section{CONCLUSIONS}

The use of the Walkasins ${ }^{\circledR}$ appears to have led to improved gait, balance, and self-perceived stability in a patient with diabetic PN. Using sensory substitution devices may be a new intervention technique for people with gait and balance dysfunction due to PN. Additional long term clinical trials are needed to determine whether this is true and generalizable to the population of people with peripheral neuropathy. Further studies are also needed to determine the optimum residual sensory function needed to use the Walkasins ${ }^{\circledR}$ and the need for gait and balance training simultaneously.

\section{DATA AVAILABILITY STATEMENT}

The original contributions presented in the study are included in the article/supplementary material, further inquiries can be directed to the corresponding author/s.

\section{ETHICS STATEMENT}

The studies involving human participants were reviewed and approved by Wingate University Research Review Board. The patients/participants provided their written informed consent to participate in this study. Written informed consent was obtained from the individual(s) for the publication of any potentially identifiable images or data included in this article.

\section{AUTHOR CONTRIBUTIONS}

DW and LO concept, data analysis, writing, and approval of manuscript. DW provided intervention, data collection, and project coordination. LO RxFunction supplied Walkasins. GM and $\mathrm{JH}$ provided intervention, data collection, and approval of manuscript. All authors contributed to the article and approved the submitted version. 


\section{FUNDING}

Walkasins used in the study was supported by a grant, R44AG040865, from the National Institute on Aging awarded to RxFunction, Inc. Walkasins were provided by RxFunction.

\section{REFERENCES}

1. National Diabetes Statistics Report. (2017). National Center for Chronic Disease Prevention and Health Promotion, Division of Diabetes Translation, Centers for Disease control. Available online at: http://www.diabetes.org/ assets/pdfs/basics/cdc-statistics-report-2017.pdf (accessed May 16, 2018).

2. Deshpande AD, Harris-Hayes M, Schootman M. Epidemiology of diabetes and diabetes-related complications. Phys Ther. (2008) 88:1254-64. doi: 10.2522/ptj.20080020

3. Harris M, Eastman R, Cowie C. Symptoms of sensory neuropathy in adults with NIDDM in the U.S. population. Diabetes Care. (1993) 16:144652. doi: 10.2337/diacare.16.11.1446

4. Shaw JE, Zimmet PZ. The epidemiology of diabetic neuropathy. Diabetes Rev. (1999) 7:245-52.

5. Candrilli SD, Davis KL, Kan HJ, Lucero MA, Rousculp MD. Prevalence and the associated burden of illness of symptoms of diabetic peripheral neuropathy and diabetic retinopathy. J Diabetes Complicat. (2007) 21:30614. doi: 10.1016/j.jdiacomp.2006.08.002

6. Gregg EW, Sorlie P, Paulose-Ram R, Gu Q, Eberhardt MS, Wolz $M$, et al. Prevalence of lower-extremity disease in the US adult population $\geq 40$ years of age with and without diabetes: 1999-2000 national health and nutrition examination survey. Diabetes Care. (2004) 27:1591-7. doi: 10.2337/diacare.27.7.1591

7. Ziegler D, Rathmann W, Dickhaus T, Meisinger C, Mielck A, Group KS. Prevalence of polyneuropathy in pre-diabetes and diabetes is associated with abdominal obesity and macroangiopathy: the MONICA/KORA Augsburg Surveys S2 and S3. Diabetes Care. (2008) 31:464-9. doi: 10.2337/dc07-1796

8. Carp SJ. Peripheral Nerve Injury: An Anatomical and Physiological Approach for Physical Therapy Intervention. Philadelphia, PA: FA Davis Company (2015).

9. Boulton AJ, Vinik AI, Arezzo JC, Bril V, Feldman EL, Freeman R, et al. Diabetic neuropathies: a statement by the American Diabetes Association. Diabetes Care. (2005) 28:956-62. doi: 10.2337/diacare.28.4.956

10. Monfort SM, Pan X, Loprinzi CL, Lustberg MB, Chaudhari AMW. Impaired Postural control and altered sensory organization during quiet stance following neurotoxic chemotherapy: a preliminary study. Integr Cancer Ther. (2019) 18:1534735419828823. doi: 10.1177/1534735419828823

11. Lee D, Lishman J. Visual contributions to postural stability in older adults. $J$ Hum Mov Stud. (1975) 1:87-95.

12. Horak FB, Nashner LM, Diener HC. Postural strategies associated with somatosensory and vestibular loss. Exp Brain Res. (1990) 82:16777. doi: 10.1007/BF00230848

13. Brach JS, Talkowski JB, Strotmeyer ES, Newman AB. Diabetes mellitus and gait dysfunction: possible explanatory factors. Phys Ther. (2008) 88:136574. doi: $10.2522 /$ ptj.20080016

14. Alam U, Riley DR, Jugdey RS, Azmi S, Rajbhandari S, D'Août K, et al. Diabetic neuropathy and gait: a review. Diabetes Ther. (2017) 8:125364. doi: 10.1007/s13300-017-0295-y

15. Menz HB, Lord SR, St George R, Fitzpatrick RC. Walking stability and sensorimotor function in older people with diabetic peripheral neuropathy. Arch Phys Med Rehabil. (2004) 85:245-52. doi: 10.1016/j.apmr.2003.06.015

16. Camargo MR, Barela JA, Nozabieli AJ, Mantovani AM, Martinelli AR, Fregonesi CE. Balance and ankle muscle strength predict spatiotemporal gait parameters in individuals with diabetic peripheral neuropathy. Diabetes Metab Syndr. (2015) 9:79-84. doi: 10.1016/j.dsx.2015.02.004

17. Cavanagh PR, Derr JA, Ulbrecht JS, Maser RE, Orchard TJ. Problems with gait and posture in neuropathic patients with insulin-dependent diabetes mellitus. Diabet Med. (1992) 9:469-74. doi: 10.1111/j.1464-5491.1992.tb01819.x

\section{ACKNOWLEDGMENTS}

The authors acknowledge Susan L. Whitney, DPT, Ph.D. for her assistance in preparing this manuscript.

18. Richardson JK, Ching C, Hurvitz EA. The relationship between electromyographically documented peripheral neuropathy and falls. $J$ Am Geriatr Soc. (1992) 40:1008-12. doi: 10.1111/j.1532-5415.1992.tb04477.x

19. Powell MW, Carnegie DH, Burke TJ. Reversal of diabetic peripheral neuropathy with phototherapy (MIRE) decreases falls and the fear of falling and improves activities of daily living in seniors. Age Ageing. (2006) 35:116. doi: 10.1093/ageing/afi215

20. Lalli P, Chan A, Garven A, Midha N, Chan C, Brady S, et al. Increased gait variability in diabetes mellitus patients with neuropathic pain. J Diabetes Complicat. (2013) 27:248-54. doi: 10.1016/j.jdiacomp.2012.10.013

21. Blake AJ, Morgan K, Bendall MJ, Dallosso H, Ebrahim SB, Arie TH, et al. Falls by elderly people at home: prevalence and associated factors. Age Ageing. (1988) 17:365-72. doi: 10.1093/ageing/17.6.365

22. Ites KI, Anderson EJ, Cahill ML, Kearney JA, Post EC, Gilchrist LS. Balance interventions for diabetic peripheral neuropathy: a systematic review. J Geriatr Phys Ther. (2011) 34:109-16. doi: 10.1519/JPT.0b013e318212659a

23. Tofthagen C, Visovsky C, Berry DL. Strength and balance training for adults with peripheral neuropathy and high risk of fall: current evidence and implications for future research. Oncol Nurs Forum. (2012) 39:E41624. doi: 10.1188/12.ONF.E416-E424

24. Salsabili H, Bahrpeyma F, Esteki A. The effects of Task-Oriented Motor Training on gait characteristics of patients with type 2 diabetes neuropathy. J Diabetes Metab Disord. (2015) 15:14. doi: 10.1186/s40200-016-0236-8

25. Alfonso-Rosa RM, Del Pozo-Cruz B, Del Pozo-Cruz J, Sañudo B, Rogers ME. Test-retest reliability and minimal detectable change scores for fitness assessment in older adults with type 2 diabetes. Rehabil Nurs. (2014) 39:2608. doi: 10.1002/rnj.111

26. Najafi B, Talal TK, Grewal GS, Menzies R, Armstrong DG, Lavery LA. Using plantar electrical stimulation to improve postural balance and plantar sensation among patients with diabetic peripheral neuropathy: a randomized double blinded study. J Diabetes Sci Technol. (2017) 11:693701. doi: $10.1177 / 1932296817695338$

27. Wall C, Wrisley DM, Statler KD. Vibrotactile tilt feedback improves dynamic gait index: a fall risk indicator in older adults. Gait Posture. (2009) 30:1621. doi: 10.1016/j.gaitpost.2009.02.019

28. Kentala E, Vivas J, Wall C. Reduction of postural sway by use of a vibrotactile balance prosthesis prototype in subjects with vestibular deficits. Ann Otol Rhinol Laryngol. (2003) 112:404-9. doi: 10.1177/000348940311200503

29. Sienko KH, Balkwill MD, Oddsson LI, Wall C. The effect of vibrotactile feedback on postural sway during locomotor activities. J Neuroeng Rehabil. (2013) 10:93. doi: 10.1186/1743-0003-10-93

30. Wall C, Weinberg MS. Balance prostheses for postural control. IEEE Eng Med Biol Mag. (2003) 22:84-90. doi: 10.1109/MEMB.2003.1195701

31. Wall C, Wrisley D, Oddsson L. Vibrotactile feedback of mediolateral trunk tilt or foot pressure increases locomotor performance in healthy older adults-a pilot study. Conf Proc IEEE Eng Med Biol Soc. (2012) 2012:61458. doi: 10.1109/EMBC.2012.6347396

32. Bao T, Carender WJ, Kinnaird C, Barone VJ, Peethambaran G, Whitney SL, et al. Effects of long-term balance training with vibrotactile sensory augmentation among community-dwelling healthy older adults: a randomized preliminary study. J Neuroeng Rehabil. (2018) 15:5. doi: 10.1186/s12984-017-0339-6

33. Ma CZ, Wong DW, Lam WK, Wan AH, Lee WC. Balance improvement effects of biofeedback systems with state-of-the-art wearable sensors: a systematic review. Sensors (Basel). (2016) 16:434. doi: 10.3390/s16040434

34. Shull PB, Damian DD. Haptic wearables as sensory replacement, sensory augmentation and trainer - a review. J Neuroeng Rehabil. (2015) 12:59. doi: 10.1186/s12984-015-0055-Z 
35. Kingma H, Felipe L, Gerards MC, Gerits P, Guinand N, PerezFornos A, et al. Vibrotactile feedback improves balance and mobility in patients with severe bilateral vestibular loss. J Neurol. (2019) 266:19-26. doi: 10.1007/s00415-018-9133-z

36. Oddsson LIE, Bisson T, Cohen HS, Jacobs L, Khoshnoodi M, Kung D, Lipsitz LA, et al. The effects of a wearable sensory prosthesis on gait and balance function after 10 weeks of use in persons with peripheral neuropathy and high fall risk - the walk2wellness trial. Front Aging Neurosci. (2020) 12:592751. doi: 10.3389/fnagi.2020.592751

37. Koehler-McNicholas SR, Danzl L, Cataldo AY, Oddsson LIE. Neuromodulation to improve gait and balance function using a sensory neuroprosthesis in people who report insensate feeta randomized control cross-over study. PLoS ONE. (2019) 14:e0216212. doi: 10.1371/journal.pone.0216212

38. Powell LE, Myers AM. The activities-specific balance confidence (ABC) scale. J Gerontol A Biol Sci Med Sci. (1995) 50:M2834. doi: 10.1093/gerona/50A.1.M28

39. Cohen HS, Kimball KT, Adams AS. Application of the vestibular disorders activities of daily living scale. Laryngoscope. (2000) 110:12049. doi: 10.1097/00005537-200007000-00026

40. Wrisley DM, Marchetti GF, Kuharsky DK, Whitney SL. Reliability, internal consistency, and validity of data obtained with the functional gait assessment. Phys Ther. (2004) 84:906-18. doi: 10.1093/ptj/84.10.906

41. Franchignoni F, Horak F, Godi M, Nardone A, Giordano A. Using psychometric techniques to improve the Balance Evaluation Systems Test: the mini-BESTest. J Rehabil Med. (2010) 42:323-31. doi: 10.2340/1650197 7-0537

42. Podsiadlo D, Richardson S. The timed "Up \& Go": a test of basic functional mobility for frail elderly persons. J Am Geriatr Soc. (1991) 39:1428. doi: 10.1111/j.1532-5415.1991.tb01616.x

43. Shumway-Cook A, Woollacott M, Kerns KA, Baldwin M. The effects of two types of cognitive tasks on postural stability in older adults with and without a history of falls. J Gerontol A Biol Sci Med Sci. (1997) 52:M23240. doi: 10.1093/gerona/52A.4.M232

44. Dal Bello-Haas V, Klassen L, Sheppard MS, Metcalfe A. Psychometric properties of activity, self-efficacy, and quality-of-life measures in individuals with Parkinson disease. Physiother Can. (2011) 63:47-57. doi: 10.3138/ptc.2009-08

45. Moore DS, Ellis R, Kosma M, Fabre JM, McCarter KS, Wood RH. Comparison of the validity of four fall-related psychological measures in a community-based falls risk screening. Res Q Exerc Sport. (2011) 82:54554. doi: 10.1080/02701367.2011.10599787

46. Myers AM, Powell LE, Maki BE, Holliday PJ, Brawley LR, Sherk W. Psychological indicators of balance confidence: relationship to actual and perceived abilities. J Gerontol A Biol Sci Med Sci. (1996) 51:M3743. doi: 10.1093/gerona/51A.1.M37

47. Myers AM, Fletcher PC, Myers AH, Sherk W. Discriminative and evaluative properties of the activities-specific balance confidence (ABC) scale. $J$ Gerontol A Biol Sci Med Sci. (1998) 53:M287-94. doi: 10.1093/gerona/53 A.4.M287

48. Wang YC, Sindhu B, Lehman L, Li X, Yen SC, Kapellusch J. Rasch analysis of the activities-specific balance confidence $(\mathrm{abc})$ scale in older adults seeking outpatient rehabilitation services. J Orthop Sports Phys Ther. (2018) 48:57483. doi: 10.2519/jospt.2018.8023

49. Cohen HS. Use of the vestibular disorders activities of daily living scale to describe functional limitations in patients with vestibular disorders. $J$ Vestib Res. (2014) 24:33-8. doi: 10.3233/VES-130475

50. Marques A, Cruz J, Quina S, Regêncio M, Jácome C. Reliability, agreement and minimal detectable change of the timed up \& go and the 10meter walk tests in older patients with COPD. COPD. (2016) 13:27987. doi: 10.3109/15412555.2015.1079816

51. Combs SA, Diehl MD, Filip J, Long E. Short-distance walking speed tests in people with Parkinson disease: reliability, responsiveness, and validity. Gait Posture. (2014) 39:784-8. doi: 10.1016/j.gaitpost.2013. 10.019

52. Ries JD, Echternach JL, Nof L, Gagnon Blodgett M. Test-retest reliability and minimal detectable change scores for the timed "up \& go" test, the six-minute walk test, and gait speed in people with Alzheimer disease. Phys Ther. (2009) 89:569-79. doi: 10.2522/ptj.20080258

53. Hoxie RE, Rubenstein LZ. Are older pedestrians allowed enough time to cross intersections safely? J Am Geriatr Soc. (1994) 42:241-4. doi: 10.1111/j.1532-5415.1994.tb01745.x

54. Goldberg A, Schepens S. Measurement error and minimum detectable change in 4-meter gait speed in older adults. Aging Clin Exp Res. (2011) 23:40612. doi: 10.1007/BF03325236

55. Shumway-Cook A, Woollacott MH. Motor Control: Theory and Practical Applications. Philadelphia, PA: Williams and Wilkins (1995).

56. Chan AC, Pang MY. Assessing balance function in patients with total knee arthroplasty. Phys Ther. (2015) 95:1397-407. doi: 10.2522/ptj.20140486

57. Leddy AL, Crowner BE, Earhart GM. Functional gait assessment and balance evaluation system test: reliability, validity, sensitivity, and specificity for identifying individuals with Parkinson disease who fall. Phys Ther. (2011) 91:102-13. doi: 10.2522/ptj.20100113

58. Marchetti GF, Lin CC, Alghadir A, Whitney SL. Responsiveness and minimal detectable change of the dynamic gait index and functional gait index in persons with balance and vestibular disorders. J Neurol Phys Ther. (2014) 38:119-24. doi: 10.1097/NPT.0000000000000015

59. Petersen C, Steffen T, Paly E, Dvorak L, Nelson R. Reliability and minimal detectable change for sit-to-stand tests and the functional gait assessment for individuals with Parkinson Disease. J Geriatr Phys Ther. (2017) 40:2236. doi: 10.1519/JPT.0000000000000102

60. Walker ML, Austin AG, Banke GM, Foxx SR, Gaetano L, Gardner LA, et al. Reference group data for the functional gait assessment. Phys Ther. (2007) 87:1468-77. doi: 10.2522/ptj.20060344

61. Wrisley DM, Kumar NA. Functional gait assessment: concurrent, discriminative, and predictive validity in community-dwelling older adults. Phys Ther. (2010) 90:761-73. doi: 10.2522/ptj.200 90069

62. Yang Y, Wang Y, Zhou Y, Chen C, Xing D. Reliability of functional gait assessment in patients with Parkinson disease: interrater and intrarater reliability and internal consistency. Medicine. (2016) 95:e4545. doi: 10.1097/MD.0000000000004545

63. Thieme H, Ritschel C, Zange C. Reliability and validity of the functional gait assessment (German version) in subacute stroke patients. Arch Phys Med Rehabil. (2009) 90:1565-70. doi: 10.1016/j.apmr.2009. 03.007

64. Beninato M, Fernandes A, Plummer LS. Minimal clinically important difference of the functional gait assessment in older adults. Phys Ther. (2014) 94:1594-603. doi: $10.2522 / \mathrm{ptj} .20130596$

65. Godi M, Franchignoni F, Caligari M, Giordano A, Turcato AM, Nardone A. Comparison of reliability, validity, and responsiveness of the mini-BESTest and Berg Balance Scale in patients with balance disorders. Phys Ther. (2013) 93:158-67. doi: 10.2522/ptj.20120171

66. Viveiro LAP, Gomes GCV, Bacha JMR, Carvas Junior N, Kallas ME, Reis $\mathrm{M}$, et al. Reliability, validity, and ability to identity fall status of the berg balance scale, balance evaluation systems Test (BESTest), MiniBESTest, and Brief-BESTest in older adults who live in nursing homes. J Geriatr Phys Ther. (2019) 42:E45-54. doi: 10.1519/JPT.00000000000 00215

67. Yingyongyudha A, Saengsirisuwan V, Panichaporn W, Boonsinsukh R. The Mini-Balance Evaluation Systems Test (Mini-BESTest) demonstrates higher accuracy in identifying older adult participants with history of falls than do the bestest, berg balance scale, or timed up and go test. J Geriatr Phys Ther. (2016) 39:64-70. doi: 10.1519/JPT.00000000000 00050

68. Trueblood PR, Hodson-Chennault N, McCubbin A, Youngclarke D Performance and impairment-based assessments among community dwelling elderly: sensitivity and specificity. Iss Aging. (2001) 24:2-6. doi: 10.1519/00139143-200124010-00001

69. Lyons SS. Evidence-based protocol: fall prevention for older adults. J Gerontol Nurs. Nov. (2005) 31:9-14. doi: 10.3928/0098-9134-20051101-05

70. Horak FB, Wrisley DM, Frank J. The Balance Evaluation Systems Test (BESTest) to differentiate balance deficits. Phys Ther. (2009) 89:48498. doi: $10.2522 /$ ptj.20080071 
71. Shumway-Cook A, Brauer S, Woollacott M. Predicting the probability for falls in community-dwelling older adults using the Timed Up \& Go Test. Phys Ther. (2000) 80:896-903. doi: 10.1093/ptj/8 0.9 .896

Conflict of Interest: Walkasins was supplied by RxFunction. LO is co-inventor of the Walkasins technology and co-founder of RxFunction, Inc., the medical device startup that is commercializing Walkasins. LO is currently employed as CTO of the company, is a shareholder in the company, and a member of the Board of Directors.
The remaining authors declare that the research was conducted in the absence of any commercial or financial relationships that could be construed as a potential conflict of interest.

Copyright $\odot 2021$ Wrisley, McLean, Hill and Oddsson. This is an open-access article distributed under the terms of the Creative Commons Attribution License (CC BY).

The use, distribution or reproduction in other forums is permitted, provided the original author(s) and the copyright owner(s) are credited and that the original publication in this journal is cited, in accordance with accepted academic practice. No use, distribution or reproduction is permitted which does not comply with these terms. 